\title{
Erratum to: The Role of General and Subject-specific Language Skills when Learning Mathematics in Elementary School
}

\author{
Stefan Ufer · Katrin Bochnik
}

Published online: 21 April 2020

(C) GDM 2020

\section{Erratum to:}

\section{J Math Didakt 2020}

https://doi.org/10.1007/s13138-020-00160-5

Because of an error during typesetting, wrong significance indicators were used in Tables $2,3,4,5$, and 6 of the initially published version of the manuscript. There, the symbols " "*: $p<0.10, * *: p<0.05, * * *: p<0.01, * * * *: p<0.001$ " were used, while the symbols "t: $p<0.10, *: p<0.05, * *: p<0.01, * * *: p<0.001$ " would have been correct. The corrected Tables 2, 3, 4, 5, and 6 are given below. The original article has been corrected.

The online version of the original article can be found under https://doi.org/10.1007/s13138-02000160-5.

S. Ufer $(\bowtie) \cdot$ K. Bochnik

Mathematisches Institut, Ludwig-Maximilians-Universität, Theresienstraße 39, 80333 München, Germany

E-Mail: ufer@math.lmu.de 


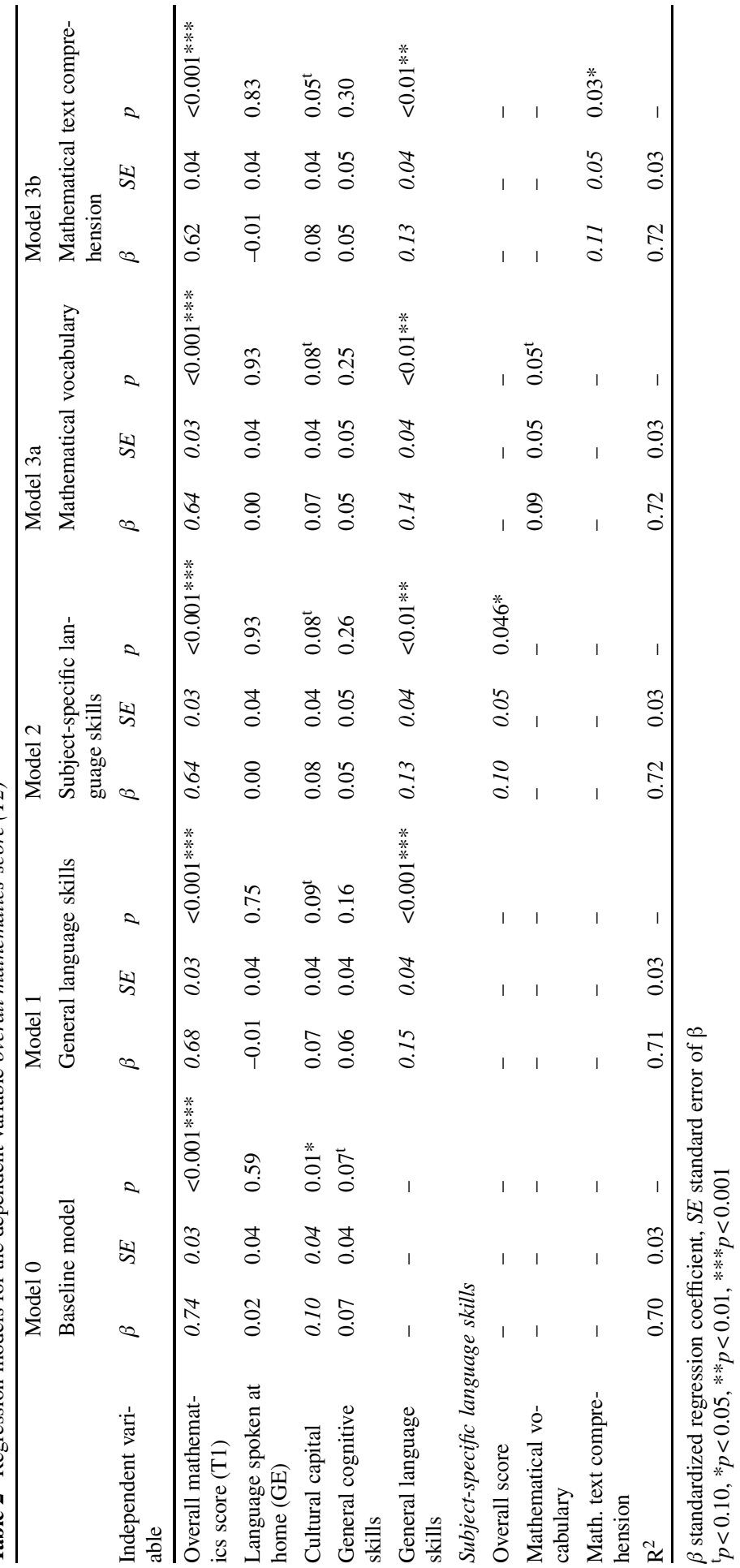




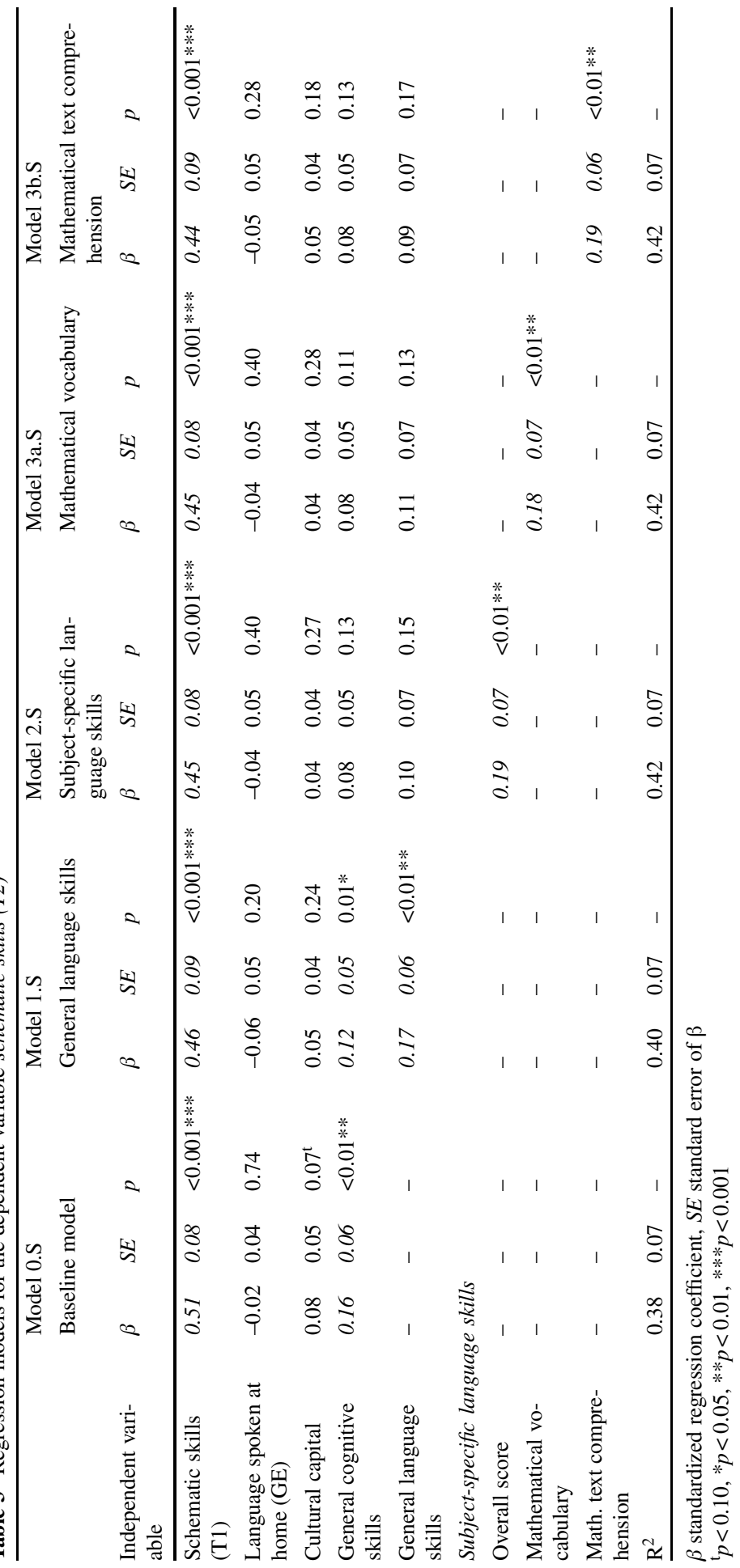




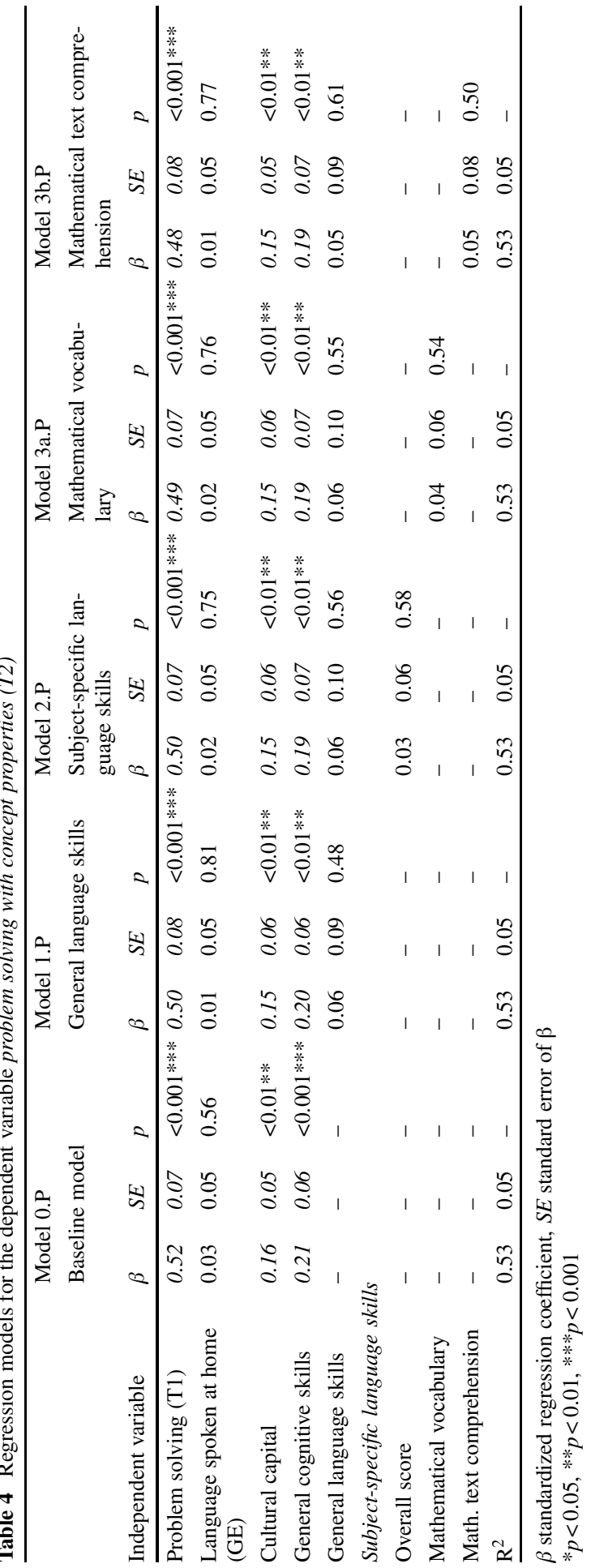




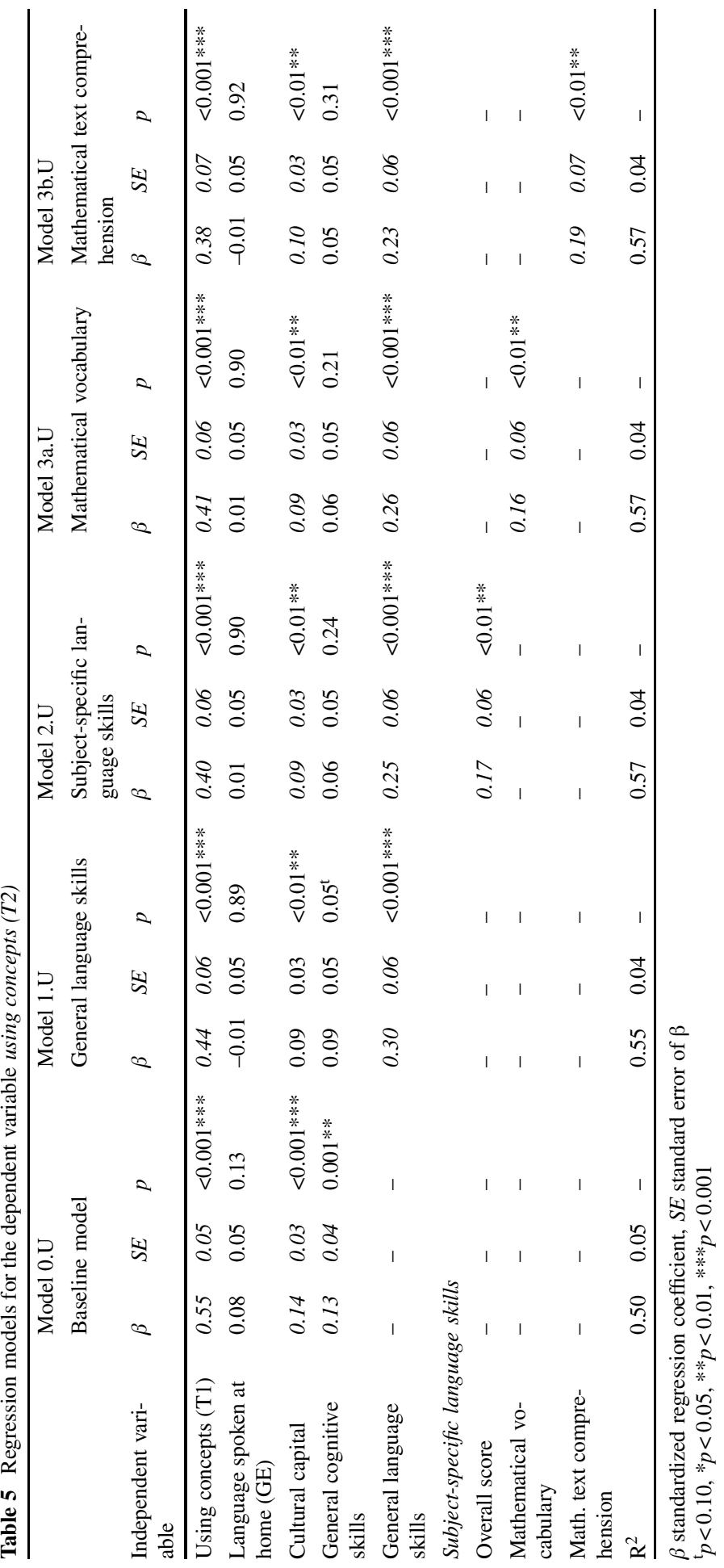




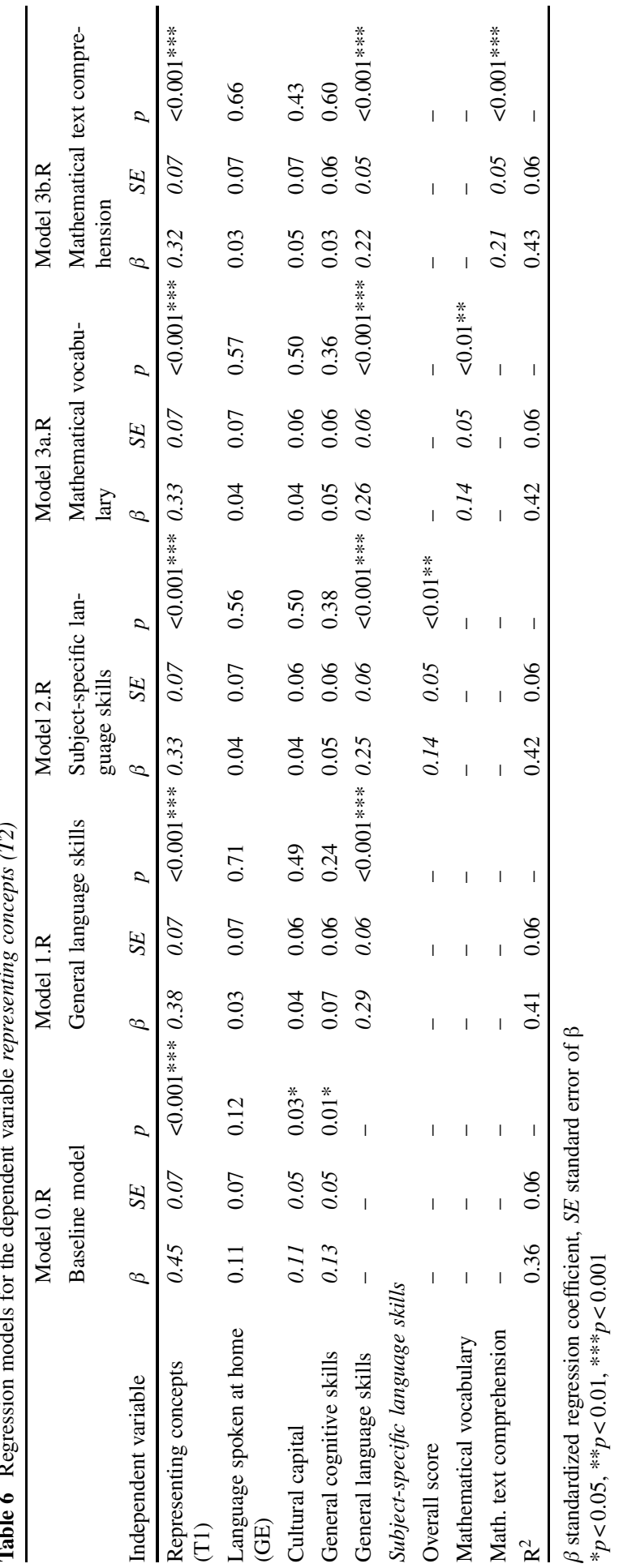

